\title{
$\mathrm{PH} 9 \mathbf{9}_{\text {actualidad }}$
}

\section{La creación colectiva rescata la memoria de las mujeres de la Siberia extremeña}

"De la tierra a las manos" es una iniciativa centrada en el papel de las mujeres en la conservación y transmisión del patrimonio cultural y natural en la Siberia extremeña, zona declarada Reserva de la Biosfera en 2019 por la UNESCO. Se plantea como un proceso de recuperación de la memoria de las mujeres de los diecisiete municipios ${ }^{1}$ que componen esta comarca de la provincia de Badajoz. Durante 2019 se desarrollaron más de 125 dinámicas de trabajo colectivo; las cuales esperan ser retomadas a lo largo del año 2020 para alcanzar los objetivos propuestos.

Encarna Díaz Gutiérrez | Culturaneas

Url de la contribución <www.iaph.es/revistaph/index.php/revistaph/article/view/4555>

El recorrido del proyecto se inicia en 2017, como fase primera, con las jornadas Mujeres y patrimonio natural y cultural $^{2}$, celebradas en noviembre de ese año en Herrera del Duque (Badajoz), en el marco de las Jornadas Europeas de Patrimonio. Nace con la voluntad de promover procesos de escucha, puesta en valor y reconocimiento de la vida cotidiana de las mujeres de la Siberia extreña como patrimonio, a partir de su propia voz. Para ello se establece una indisociable triangulación e interrelación de tres conceptos que caminan de la mano en entornos no urbanos: mujeres, patrimonio cultural y patrimonio natural.

El proceso general se plantea como un camino de largo recorrido para lograr la visibilidad de las mujeres que habitan zonas rurales, como agentes de transmisión del patrimonio y la conservación del entorno natural, a partir de un elemento natural comarcal, el olivo, y de su recurso productivo, el aceite. La línea vertebradora es la activación de la memoria colectiva de las mujeres y su relación con los procesos de elaboración y usos del aceite con el objetivo de dar cuenta de su protagonismo como productoras, conservadoras y transmisoras del patrimonio cultural inmaterial que gira en torno a su producción como alimento pero también como como fenómeno cultural y como elemento de identidad de la comarca. Las mujeres han estado presentes en todas las fases: desde la recogida hasta la reutilización. Ellas recibieron estos conocimientos por el hecho de ser mujeres y posteriormente los han reproducido y transmitido en diferentes

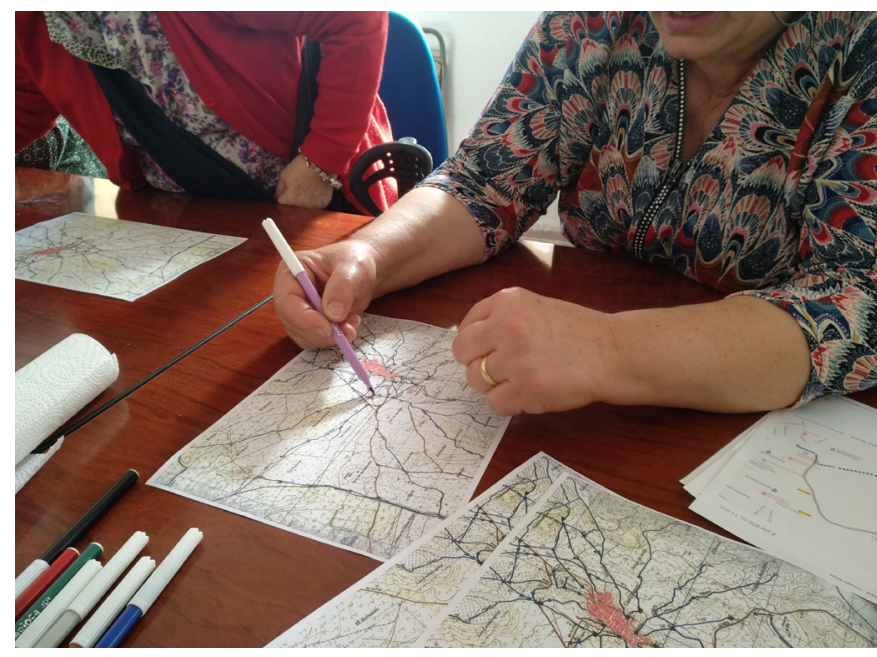

Mapeo de lugares de memoria colectiva de las mujeres (Villarta)

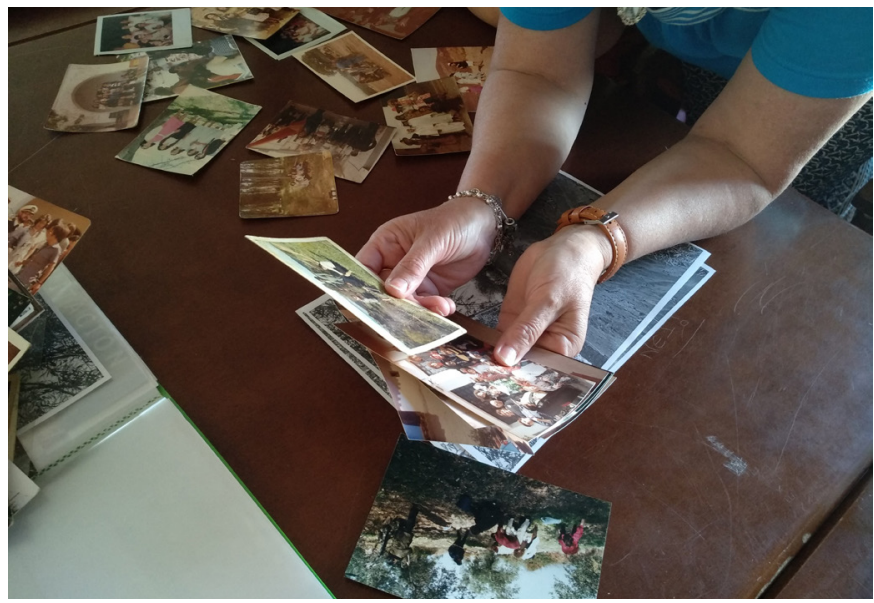

Taller Mujeres, memoria y autorepresentación: técnicas de collage (Risco) 
espacios: naturales, públicos y domésticos. A pesar de este papel activo, la imagen de su presencia ha sido borrada de ciertos lugares y espacios. A partir de aquí, y de manera paralela, se activan los mecanismos para la reinterpretación de los imaginarios de género en el sector y se propicia el intercambio del conocimiento entre generaciones, la identificación de redes de mujeres y el fomento de liderazgos.

La segunda de las fases, denominada Memoria colectiva de las mujeres de la Siberia extremeña, se centra en la recuperación de la memoria de las mujeres y se ha venido desarrollando a lo largo del año 2019 a tra-

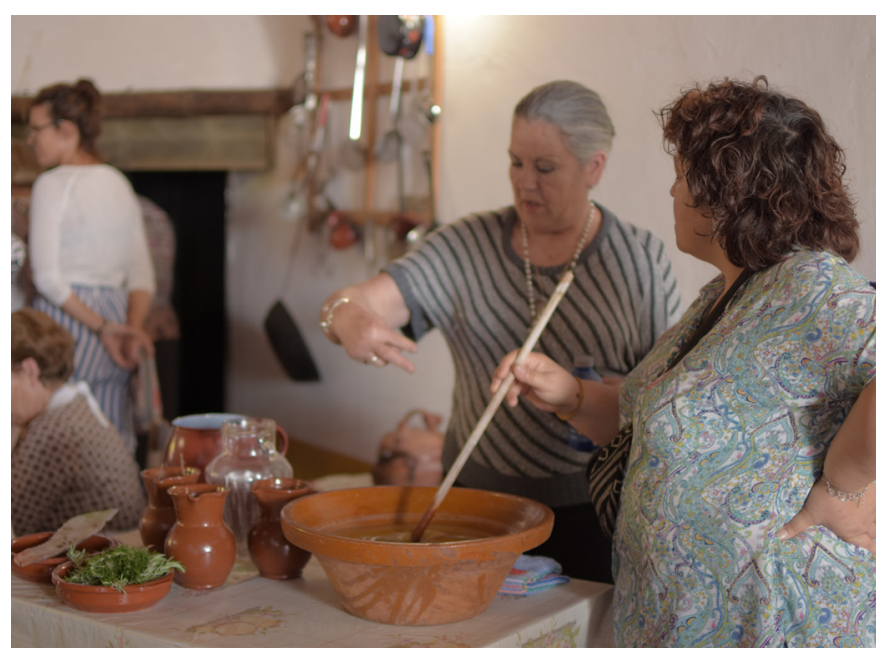

Taller colaborativo de elaboración de jabón (Tamurejo)

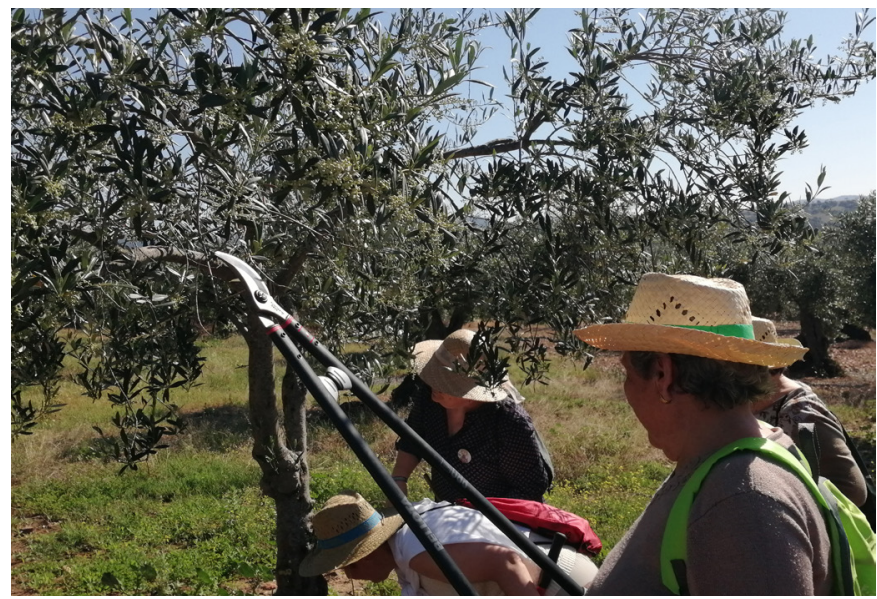

Taller de poda y quema (Garlitos) vés de dinámicas participativas que se articulan como un proceso de creación colectiva, en forma de mapeos de rutas y lugares comunes en los imaginarios colectivos de las mujeres (testimonios orales y visuales de memoria), resignificación de imágenes a partir de técnicas de collage, para la autorrepresentación (análisis de tareas, lugares y objetos de trabajo), piezas cantadas a partir de la revisión del folklore local... El trabajo de diseño de estas dinámicas ha sido desarrollado por la gestora cultural y comisaria extremeña Amparo Moroño y coordinado por mujeres especialistas en cada una de las técnicas empleadas (collagistas como Rebeka Elizegi, gestoras culturales, especialistas en folklore, creadoras visuales...). La dinamización de las sesiones se lleva a cabo por gestoras culturales de la comarca.

Estas actividades tienen como principal reto armar un relato y se realizan en colaboración con los colectivos de mujeres de los diferentes pueblos. Los resultados de este trabajo compondrán el cuerpo de la tercera fase: una exposición colectiva que itinerará por todos los muncipios de la comarca y que será presentada al público en general por sus protagonistas a partir de visitas guiadas y actividades específicas. El inicio de esta fase aún se encuentra por concretar.

El trabajo previo a la exposición es de vital importancia para el desarrollo del proyecto y constituye su núcleo principal y su razón de ser. Los grupos de mujeres son el espacio de pensamiento y creación donde se genera el conocimiento colectivo que se alcanza a partir de los saberes y las experiencias que aporta cada participante. Este lugar permite reconocerse y autorreconocerse, valorarse de manera individual y colectiva dentro del proceso productivo y cultural así como ser conscientes del peso e importancia de su trabajo y de su contribución al desarrollo cultural, social y económico de la comarca.

Culturaneas -Cultura. Igualdad. Diversidad-diseña y ejecuta el proyecto de manera paralela a la candidatura de Reserva de la Biosfera de La Siberia dentro del Programa Hombre y Biosfera (MaB) promovido por la UNESCO, hoy ya reconocida como tal. Al tratarse de un proyecto con un gran alcance, los agentes implicados son numerosos; además de los colectivos de mujeres, es indispensable 


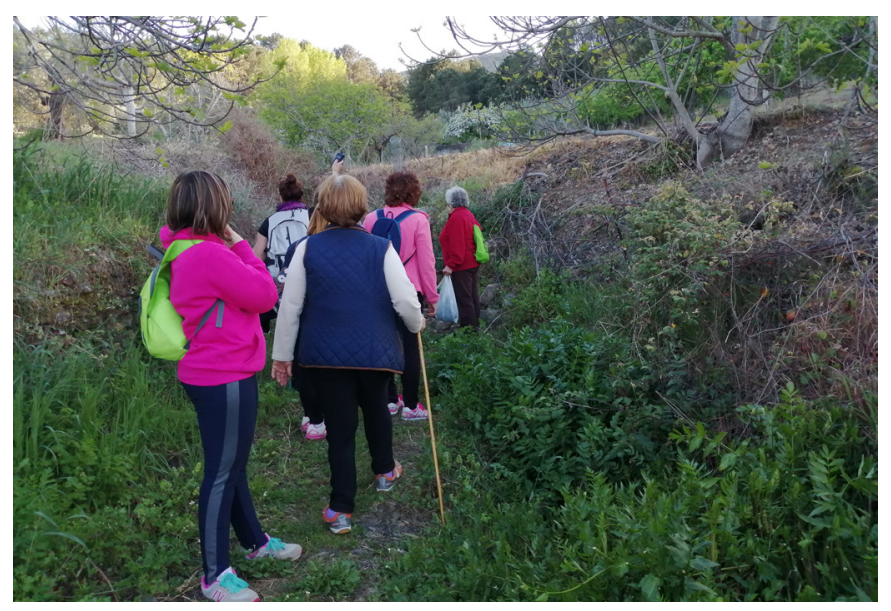

Paseo fotográfico Mujeres y entorno natural -lugares de memoria(Valdecaballeros) | fuente Culturaneas, de todas las imágenes

contar con el apoyo de ayuntamientos de los municipios, Centro de Desarrollo Local "La Siberia", mancomunidades, centros sociales y culturales de las localidades, asociaciones y colectivos socioculturales, cooperativas olivareras de la comarca, comunidad educativa...

El proyecto ha contado con el apoyo de la Consejería de Cultura e Igualdad de la Junta de Extremadura y la Red de Desarrollo Rural de Extremadura, El Centro de Desarrollo Rural La Siberia y el Ayuntamiento de Herrera del Duque en la primera de sus fases (jornadas Mujeres y Patrimonio Cultural y Natural en 2017). La Diputación de Badajoz financia la puesta en marcha de la fase denominada Historia colectiva de las mujeres de la Siberia extremeña (2019) 3 con el apoyo de los ayuntamientos, Ceder "La Siberia", la asociación de Mujeres "La flor de Jara" de Herrera del Duque y el resto de asociaciones de mujeres de todos los municipios.

\section{Proyecto de Culturaneas}

Coordinación general: Encarna Díaz Gutiérrez

Dirección artística y comisariado: Amparo Moroño Díaz

Dinamización de actividades: Antonia García Risco, Ana Isabel

Sánchez Martín

Aseosoramiento artístico: Rebeka Elizegi

Vídeo: Imago Bubo Rural Colectivo

Diseño de imagen: Ana Silvero

\section{NOTAS}

1. Las localidades que conforman la comarca de la Siberia (Badajoz) son Baterno, Casas de Don Pedro, Catilblanco, Esparragosa de Lares, Fuenlabrada de los Montes, Garbayuela, Garlitos, Helechosa de los Montes, Herrera del Duque, Puebla de Alcocer, Risco, Sancti-Spiritus, Siruela, Talarrubias, Tamurejo, Valdecaballeros y Villarta de los Montes.

2. Vídeo de las jornadas Mujeres patrimonio cultural y natural (2017): https://www.youtube.com/watch?v=Z7k $6 \mathrm{k} 43 \mathrm{HevY}$

3. Vídeo resumen de la fase de dinámicas participativas Historia colectiva de las mujeres de la Siberia extremeña (2019): https://youtu.be/7ieWeeVSIU4

\section{BIBLIOGRAFÍA}

- JIMÉNEZ-ESQUINAS, G. (2017) El patrimonio (también) es nuestro. Hacia una crítica patrimonial feminista. En ARRIETA URTIZBEREA, I. (ed.) El género del patrimonio cultural. Bilbao: EHU/UPV, 2017 pp. 19-48

- QUIROSA-GARCÍA, V.; GÓMEZ-ROBLES, L. (2010) El papel de la mujer en la conservación y trasmisión del patrimonio cultural. Asparkia: investigación feminista [en línea], n. ${ }^{\circ} 21,2010$, pp. 75-90 <http://www.e-revistes.uji.es/index.php/ asparkia/article/view/440> [Consulta: 13/12/2019]

- LATRE, C. M. (2009) ¿Tiene sexo el patrimonio? Museos. Es: revista de la Subdirección General de Museos Estatales, n. ${ }^{\circ} 5,2009$, pp. $138-151$

- PÉREZ-RUBIO, J. A.; SÁNCHEZ-ORO, M.; GARCÍAGARCÍA, Y. (2015) Mujer rural en Extremadura. Proceso de empoderamiento y aportaciones al capital social. Cáceres: Universidad de Extremadura, 2015

- MARCos ARÉVALO, J. (2018) La Siberia Extremeña en la Voz de su gente (el etnógrafo y los informantes). Badajoz: Fundación CB, Universidad de Extremadura, 2018 